\title{
Связь между публичной и военной дипломатией во внешней и оборонной политике
}

\author{
Геран Свистек
}

\section{Введение}

Идея «публичной дипломатии» была применена приблизительно сто лет назад как совершенно гражданский аспект дипломатии, чей смысл был информировать иностранное население и граждан о целях внешней политики данной страны путем использования информационных и культурных программ. ${ }^{1}$ В рамках философии Клаузевица, который считал, что «война является продолжением политики другими средствами», вооруженные силы всегда были связаны с дипломатической сферой, но никогда не являлись ее частью. ${ }^{2}$ С другой стороны, долгое время «военная дипломатия означала только работу военных атташе»; их задача была «быть глазами и ушами страны в дни, которые предшествовали появлению спутниковой фотографии и изощренных технологий сбора электронной информации». ${ }^{3}$

Вместе с изменениями, которые произошли на международной арене за последние несколько десятков лет, особенно в том, что касается образования нового созвездия альянсов, пересмотра целей внешней политики и изменения предполагаемых угроз, изменилось и содержание публичной дипломатии, а ее целевые программы расширились. ${ }^{4} \mathrm{~B}$ то же время, после падения «Железного занавеса» и распада Советского Союза, изменились понимание и дефиниция концепции безопасности. В наши дни безопасность определяется прежде всего представлением о «комплексном подходе». Безопасность рассматривается как набор связей между гражданскими и военными средствами и подходами, тогда как использование военной силы остается последним располагаемым средством. Поэтому программы и средства в областях военной и публичной дипломатии пользуются повышенным вниманием и приобрели более высокий статус.

\footnotetext{
Коммодор, дипломированный политолог, Геран Свистек, MCGI, является морским офицером, сейчас он капитан немецкого военного корабля ФРЕТХЕН и имеет образовательную степень по политическим наукам, а так же по лидерству и менеджменту. Он выпускник Лидерской Программы Передовых Оборонных Исследований 2011 года. Сейчас участвует в магистерской программе по международной безопасности Центра им. Джорджа К. Маршала. Область его компетентности - это международные отношения; политика и стратегия безопасности; исследования мира и конфликтов; современные способы военных действий.

1 Walter R. Roberts, "What is Public Diplomacy? Past Practices, Present Conduct, Possible Future," Mediterranean Quarterly 18:4 (2007): 37.

2 Carl von Clausewitz, On War, Chapter 1, Para. 24 (Project Gutenberg E-Book No. 1946, 25 February 2006); доступно на: www.gutenberg.org/files/1946/1946-h/1946-h.htm.

3 Timothy C. Shea, “Transforming Military Diplomacy,” Joint Force Quarterly 38 (2005): 50.

4 Roberts, "What is Public Diplomacy?"
} 
По этой причине в настоящем эссе будет сделана попытка проследить близкие отношения современных оборонных стратегий, политики и дипломатии. Основной проблемой, которая будет исследована в этом эссе является следующая: существуют ли в современной внешней и оборонной политике отношения между военной дипломатией и публичной дипломатией? И если существуют, то чем характеризуются эти отношения? Следуя этой линии, в статье будет исследована связь между публичной дипломатией и военной дипломатией, полагая, что международные отношения и оборонная политика нацелены на перекрывающиеся области, особенно когда речь идет о дипломатии. Следовательно, можно сформулировать следующую гипотезу: без упоминания в официальных политических документах и без сформулированной стратегии, в последнее время расширилась сфера, где публичная дипломатия и военная дипломатия действуют согласованно, применяя общие инструменты. Я буду использовать пример вооруженных сил Германии, как специальный объект исследования, чтобы продемонстрировать, как они уже десятки лет действительно применяют публичную дипломатию в районах своего расположения.

Как первый шаг, в статье будет предложен общий обзор идеи, дефиниций и разных концепций публичной дипломатии, который обеспечит основу для дальнейших наблюдений. В отличие от этого, краткое знакомство с идеей и концепцией военной дипломатии покажет подход с другой точки зрения. На третьем этапе статья высветит общие стратегии и инструменты, чтобы показать общие и подобные области. Следуя этим этапам, в статье будут представлены два тематических исследования, проведенные в вооруженных силах Германии, которые проиллюстрируют сформулированную выше гипотезу на основании наблюдений из предыдущих двух этапов. В итоге, в заключении статьи будут сформулированы некоторые общие выводы об отношениях между публичной и военной дипломатией в наше время.

\section{Концепция публичной дипломатии}

Публичная дипломатия в определенной степени является продолжением традиционной дипломатии, той ее части, которая связана с финансируемыми правительством программами и инициативами, предназначенными оказывать влияние на и информировать иностранную аудиторию. Эти программы иногда называют «международной информацией» или «культурными» программами. Обычно их используют для того, чтобы передать определенное послание, касающееся внешней политики страны, политических целей, мероприятий по экономическому сотрудничеству или даже развития туристических возможностей.

Для концепции публичной дипломатии органически естественно то, что адресатами ее деятельности являются в основном неправительственные акторы. Однако, публичная дипломатия стремится к стимулированию международного понимания и к инициированию диалога между вовлеченными странами и между акторами, принимающими решения. Поэтому действия традиционной публичной дипломатии были нацелены на создание такого понимания через информацион- 
ные, языковые и культурные программы. Программы публичной дипломатии были построены на двух столбах: первый, информационный, можно было бы сравнить с традиционным элементом связи с общественностью; второй состоит из достижения понимания политик и идеологий. Вторая часть в особенности является двусторонним процессом, в котором страна пытается сделать понятной для иностранного населения свою конкретную политику, но также старается понять политику чужих стран. Конкретные частные действия в рамках этого двухколонного подхода варьируют, к примеру, от общих академических программ и обменов, сотрудничества в области культуры, информационно-пропагандистских программ и туристической рекламы, до учреждения языковых институтов и организации совместных научных и художественных проектов.

В последние годы вместе с развитием комплексного подхода к ряду новых угроз безопасности и к изменениям в понимании термина безопасности, публичная дипломатия снова сместила фокус своих усилий к внешним отношениям как стратегия, как инструмент межнационального взаимодействия и как механизм для развития взаимозависимостей и следовательно, поддерживания и расширения мира.

Таким образом, к зданию публичной дипломатии был добавлен новый столб: влияние на внешнюю политику. Этот элемент предназначен для оказания давления на людей, принимающих решения в иностранных правительства и на сами решения. ${ }^{5}$ Даже когда действия публичной дипломатии идут из правительств или органов власти, публичная дипломатия не стремится к прямому влиянию на иностранные правительства и на людей, принимающих решения. Создавая положительный климат среди иностранного населения, страны, которые генерируют кампании публичной дипломатии, пытаются содействовать целям и задачам своей внешней политики. ${ }^{6}$

Некогда посол был основным игроком на поле публичной дипломатии, но в наши дни акторы, вовлеченные в такие кампании, многочисленны и разнообразны по характеру. Посол, как старший дипломат в данной чужой стране, все еще остается основным источником дипломатических посланий и действий, но действия на месте (и в особенности вдали от посольства), обычно являются ответственностью других финансируемых правительством органов, многонациональных организаций, сетей сотрудничества и неправительственных организации. ${ }^{7}$ В этом же направлении и на военных в последнее время тоже была возложена большая ответственность в сфере публичной дипломатии в некоторых странах.

\section{Что такое военная дипломатия?}

Параллельно определению публичной дипломатии, термин военная дипломатия (или как еще часто говорят дипломатия в сфере обороны) был и остается тесно

5 Roberts, "What is Public Diplomacy?," 45.

Там же, 46.

7 Там же, 50. 
связанным с ролью военного атташе. ${ }^{8}$ Атташе, как помощник посла, является дипломатом в форме с полным дипломатическим статусом, чья обязанность когда-то была наблюдать и оценивать военное развитие в иностранном государстве, а так же поддерживать близкие отношения с военной элитой чужого государства. Эта практика появилась как часть европейской дипломатии девятнадцатого века, и осталась почти без изменений до середины 1980-х. ${ }^{9}$ Существенный сдвиг в характере и целях международных военных отношений произошел вместе с падением Железного занавеса. С изменением понимания безопасности в сторону комплексного подхода к ее укреплению, роль военного атташе и его обязанности соответственно расширились. Вдобавок военный атташе уже не является единственным военным актором в сфере военной дипломатии. Понятие и современное восприятие военной дипломатии может быть определено следующим образом: «Обеспечивать средства для разнообразных мероприятий, предпринимаемых министерством обороны с целью рассеять враждебное отношение, установить и поддерживать доверие, помогать развитию демократически подотчетных вооруженных сил, и таким образом вносить вклад в предотвращение и разрешение конфликтов». ${ }^{10}$

Традиционная роль вооруженных сил определялась их боевыми способностями и готовностью использовать силу и угрозы в целях обороны, сдерживания, принуждения или интервенции. ${ }^{11}$ Военная дипломатия в наши дни является в основном мирновременным занятием и стала основной задачей для вооруженных сил и соответствующих министерств. Ее рамки определяются сотрудничеством с союзниками и другими чужими странами, особенно с теми, что проходят через процесс перехода к пост-конфликтным и демократическим обществам, и там, где она может быть использована как инструмент для содействия современной внешней политике и политике безопасности. ${ }^{12}$ В рамках комплексного подхода к безопасности военная дипломатия является одним из основных несущих столбов.

Конкретными видами деятельностями, входящими в концепцию военной дипломатии с точки зрения США, являются:

- Создание двухсторонних и многосторонних контактов между высшими военными и гражданскими официальными лицами;

- Назначения военных атташе;

- Двухсторонние соглашения о сотрудничестве в сфере обороны;

8 Shea, "Transforming Military Diplomacy," 50.

9 Andrew Cottey and Anthony Forster, "Introduction to Reshaping Defence Diplomacy: New Roles for Military Cooperation and Assistance," в Reshaping Defence Diplomacy: New Roles for Military Cooperation and Assistance (London: Routledge, Chapman \& Hall, 2004).

10 United Kingdom Ministry of Defence, "Defence Diplomacy," MoD Policy Paper 1 (December 2000), 2; доступно на www.mod.uk/DefenceInternet/AboutDefence/CorporatePublications/ PolicyStrategyandPlanning/PolicyPapers/PolicyPaperNo1DefenceDiplomacy.htm.

11 Cottey and Forster, "Introduction to Reshaping Defence Diplomacy."

12 Там же. 
- Деятельности по подготовке иностранного военного и гражданского персонала для оборонных ведомств;

- Предоставление знаний, опыта и консультаций по проблемам демократического контроля над вооруженными силами, менеджменту обороны и по военно-техническим вопросам;

- Обмен военным персоналом;

- Предоставление военной поддержки и помощи материалами и оборудованием. $^{13}$

Это извлечение очень похоже на основные задачи и конкретные миссии, идентифицированные министерством обороны Великобритании в докладе о военной дипломатии, опубликованном в декабре 2000 года. Благодаря этому докладу правительство Объединенного королевства стало первым правительством, которое выдвинуло усиление роли военной дипломатии в качестве основной обязанности вооруженных сил. Основные задачи, названые в этом докладе, были:

- Контроль за вооружениями, нераспространение и меры по установлению доверия и безопасности;

- Оказание помощи группам населения в социально невыгодном положении;

- Другие виды деятельности, касающиеся военной помощи и не охваченные программами по оказанию помощи группам в социально невыгодном положении. $^{14}$

В рамках этих крупных задач министерство обороны Объединенного королевства идентифицировало следующие конкретные миссии, которые вооруженные силы должны выполнять как часть дипломатических усилий:

- Курсы подготовки и программы обучения;

- Предоставление инструкторов по найму или в качестве гражданских и военных советников;

- Визиты кораблей, самолетов или других военных единиц;

- Визиты министров, военного и гражданского персонала всех уровней;

- Встречи и разговоры личного состава, конференции, семинары и др. для улучшения взаимного понимания;

- Обмен персоналом;

- Совместные учения. $^{15}$

13 Там же, Таблица 1.

14 U.K. Ministry of Defence, "Defence Diplomacy," 5-14.

15 Там же, 4-5. 
В целом наблюдается сдвиг военной дипломатии в сторону ее превращения в инструмент предотвращения кризисов, их раннего предупреждения и пост-конфликтной перестройки в огромной сфере внешней политики и политики безопасности. Военную дипломатию используют при попытках обеспечить стабильность и безопасность, изменяя отношение и понимание сторон конфликта; поэтому это «есть то самое разоружение ума, которое характеризует» военную дипломатию. ${ }^{16}$ Таким образом, основную цель дальнейшего развития безопасности можно описать просто как установление партнерств и расширение возможностей этих партнерств.

\section{Общая стратегия и общие инструменты}

После того как была рассмотрена первоначальная концепция и развитие публичной дипломатии, а также менее известная сфера военной дипломатии, становится ясно, что эти два вида деятельности имеют пересекающиеся сферы ответственности и действий в современной внешней политике и политике безопасности. Обе они направлены на информирование и оказание влияния на иностранную аудиторию путем реализации программ сотрудничества, информационных программ и программ по укреплению доверия. Тогда как военная дипломатия сначала претендовала на то, что она занимается только очень чувствительной сферой безопасности и использования военной силы, со временем ею был разработан широкий набор инструментов, предназначенных для решения таких вопросов как достижение понимания, укрепление взаимного доверия и оказание влияния на иностранные должностные лица, причем не только на высших представителей вооруженных сил, но и на гражданских служащих, работающих в сфере безопасности и дипломатии. В отличие от военной, публичная дипломатия сфокусирована в основном на гражданском населении в чужих государствах, обычно с целью избежать любой вероятности произвести впечатление, будто она связана с военными, поэтому в общем и целом она использует репутацию неправительственных организаций. В результате обе концепции, похоже, имеют свои собственные сферы ответственности и работают на параллельных линиях, даже если они и имеют некоторые конкретные совпадающие задачи. В эпоху, когда целью является комплексный подход к безопасности-при котором безопасность, это общая задача для разных сфер политики и для всех ведомств правительства-такое дублирование функций неизбежно и даже необходимо, чтобы подходить к вопросам безопасности на разных уровнях и с разных позиций. Есть слои общества, которые отвергают сотрудничество с военными структурами, и в тоже время есть такие, к которым легче подойти с точки зрения военных. То же наблюдение относится и к публичной дипломатии. Традиционный разрыв между этими двумя областями и взаимная резервированность размываются и отходят в прошлое. Единственным остающимся возражением против этого упразднения четкого разделения между военной дипломатией и публичной является часто используемое обвинение, что публичная

16 Там же, 4. 
дипломатия (а вместе с ней - и гражданское общество) могут быть использованы военными в собственных интересах. При разделенном на этапы и синхронизированном подходе к вопросам безопасности и проблемам в чужих странах такой опасности можно избежать.

\section{Выборочное тематическое исследование вооруженных сил Германии}

Основным принципом внешней политики и политики безопасности Германии был и остается: «никогда снова, никогда самим, политика перед силой». ${ }^{17}$ По этой причине в течении последних шестидесяти лет Германия возражала и продолжает возражать против любого одностороннего использования силы и против внешней политики с военным уклоном. Оставаясь верной ценностям западных демократий, Германия реализует свою внешнюю политику и политику безопасности в своей практике сотрудничества с союзниками в соответствии с транснациональными институциями, в которых она участвует, и в европейской системе коллективной безопасности. ${ }^{18}$ Если рассматривать немецкую внешнюю политику и политику по безопасности саму по себе, то обе они представляют специфическую точку зрения гражданского общества. Дипломатия, сотрудничество, содействие развитию культурно-образовательных программ являются главными элементами международных отношений Германии. Таким всегда был традиционный немецкий подход к международным отношениям с конца Второй мировой войны, и он отражает концепцию Германии относительно строительства и использования ее вооруженных сил. По этой причине внешнюю политику и политику безопасности Германии до конца Холодной войны иронически называли «дипломатией чековой книжки», имея в виду крайнее нежелание Германии использовать силу и акцентирование в международных отношениях на щедрое финансирование языковых, культурных программ и программ развития. Это отношение-а вместе с ним и целостный облик немецкой внешней политики-изменились после первого участия вооруженных сил Германии в операциях НАТО и ООН после падения Железного занавеса и объединения Германии. Однако, фундаментальная «дипломатия чековой книжки» Германии все еще является основой сегодняшней внешней политики и политики безопасности Германии.

Следуя этому пути, Германия разработала определенный набор видов деятельности, которые часто объединяют под наименованием «Посол в голубом». Этот подход никогда не достигал статуса завершенной концепции, но с реализацией нескольких индивидуальных и внутренних миссий военно-морских сил он представ-

17 Sebastian Harnisch and Hanns W. Maull, "Conclusion: Learned its Lesson Well? Germany as a Civilian Power Ten Years after Unification," в Germany as a Civilian Power: The Foreign Policy of the Berlin Republic, под ред. Harnisch and Maull (Manchester: Manchester University Press, 2001), 128-56.

18 Christine Streichert, "Deutschland als Zivilmacht," Trierer Arbeitspapiere zur Internationalen Politik 11 (Trier: Universität Trier, 2005), 4-5; доступно на: www.deutsche-aussenpolitik.de/ resources/tazip/tazip11.pdf. 
ляет собой сочетание мероприятий, проводимых с 1970-х годов и до наших дней. Основное направление в этой сфере деятельности было и остается связанным с визитами немецких военных кораблей в иностранные государства. Обязанность кораблей, участвующих в таких визитах, состоит в том, чтобы представлять Германию, принимая официальные лица иностранного государства, показывая достижения немецкого кораблестроения и военно-морской технологии, обеспечивая поддержку мероприятий по подготовке иностранного военно-морского персонала, являясь трибуной для высших правительственных и военных лиц, и передавая предоставленные правительственными и неправительственными организациями средства иностранным проектам по развитию. Эти мероприятия способствовали работе военного или военно-морского атташе Германии в данном иностранном государстве и были направлены на улучшение отношений, поддержку ряда программ развития, обеспечение лучшего понимания политики Германии, а так же на установление деловых отношений между этими странами и Германией.

Другой сферой, в которой вооруженные силы Германии проявили уникальные способности, а так же создали специальные программы в области пересечения военной и публичной дипломатии - и в процессе этого заняли лидирующее место среди своих союзников, - является сфера гражданско-военного сотрудничества (CIvil-MIlitary Cooperation - CIMIC). Сегодня сектор гражданско-военного сотрудничества является независимой организационной частью вооруженных сил Германии (известная как ZMZ - Zivil-militärische Zusammenarbeit). ${ }^{19}$ Этот сектор разрабатывает, позиционирует и координирует мероприятия и программы, направленные на укрепление безопасности, на развитие и на идентификацию угроз и защиту от них как в самой Германии, так и в иностранных государствах, и выполняет эту задачу, координируя усилия правительственных и неправительственных организаций с мероприятиями вооруженных сил. Под девизом «нет развития без безопасности» правительство Германии в 2004 году объявило о создании провинциальных восстановительных команд (ПВК) и их развертывании в Афганистане. ${ }^{20}$ Эти команды включают рабочих, инженеров и представителей агентств по развитию и неправительственных организаций, а так же и военнослужащих из вооруженных сил. Вместе они выполняют общую задачу по ускорению восстановления гражданской инфраструктуры Афганистана, релокализацию программ развития, обеспечению безопасности мирных жителей иностранного государства и укрепления репутации немецких добровольцев и немецких военнослужащих в Афганистане. Наряду с задачей восстановления и создания базиса будущей среды безопасности, эти команды концентрируют свои усилия на установление связей с ме-

19 Больше информации о деталях деятельностей и структур Германии в сфере СIMIC можно найти на: www.auswaertiges-amt.de; www.bmvg.de; www.bundesregierung.de; www.bundeswehr.de; www.deutsche-aussenpolitik.de. Обзор текущей концепции можно найти на www.streitkraeftebasis.de/ portal/a/streitkraeftebasis/uleist/zmzi.

20 Peter Runge, "Helfer in Uniform? Militäreinsätze in der humanitären Hilfe," в Wissenschaft \& Frieden, no. 4 (2006), специальный выпуск "Zivil-militärische Zusammenarbeit”; доступно на: www.wissenschaft-und-frieden.de/seite.php?artikelID=0463. 
стными афганскими властями и высшими афганскими руководителями. Со стороны гражданских и неправительственных организаций к этому проекту подошли с большими колебаниями, так как боялись, что в глазах афганского населения команды потеряют свою репутацию независимых и добровольных помощников. Пока количество статистической информации небольшое, да и времени прошло мало, чтобы делать какие-либо заключения об успехах и достижениях этих команд, но официальные правительственные лица уже подчеркивают значение таких проектов для целостной трансформации усилий по разрешению конфликта в Афганистане и для будущей интеграции немецкого персонала в программах по партнерству. Критика этих команд была ограничена тем фактом, что Германия никогда не примет участие в операциях, в которых может быть размыта граница между мандатами вооруженных сил и неправительственных или благотворительных организаций, так как и те, и другие потеряют свою легитимность. ${ }^{21}$

\section{Заключение}

В заключение, публичная дипломатия и военная дипломатия в течении последнего столетия развивались на основе разных представлений о международных отношениях, и следовательно, были направлены на разные сферы и виды деятельности. При более комплексном и взаимозависимом подходе к вопросам безопасности в новом взаимосвязанном мире, в этих двух видах дипломатии появились общие области ответственности и общие виды деятельности, в которых ставится цель вместе добиться улучшения понимания политики данного государства, развития сотрудничества и партнерства и поддержки процессов стабилизации в контексте региональной и международной безопасности. В то же время, эти две сферы остаются четко разделенными, со специфическими целями и видами деятельности, так как они используются в различном окружении.

Военное сотрудничество-и следовательно, военная дипломатия,-сначала были частью инструментария международной realpolitik (реальной политики) для сохранения равновесия сил путем поддержки союзников и противодействия противникам. Сегодня военная дипломатия используется для того, чтобы установить и поддерживать партнерские отношения с бывшими оппонентами и новыми партнерами. Она стала одной из первых программ, задействованных в пост-конфликтных обществах с целью укрепить политику прекращения фундаментального насилия. Но у военной дипломатии есть легитимная роль и в мирных и консолидированных обществах, в которых сотрудничество и партнерство (особенно в чувствительной области безопасности) требует продолжения общих усилий. Создание прочной и долговременной безопасности и стабильности остается определяющей целью.

Подобные предположения можно сделать и о секторе публичной дипломатии. Бывшая некогда просто инструментом, используемым в попытке информировать и коммуникировать общее понимание политики данного государства в иностран-

21 Там же. 
ном обществе, сегодня она стала интегральной частью более широкого подхода к международной безопасности, в котором главной задачей является влияние на общества иностранных государств по каналам гражданского общества. Но это в меньшей степени попытка убедить в чем-то иностранное общество, чем попытка обеспечить поддержку в процессе самоопределения свободного, равного и независимого общества.

Обе исследованных области, как и было предположено, развивались в соответствии с сегодняшними общими условиями международных отношений и стали очень близко связанными областями в области внешней политики и политики безопасности. Обе можно и нужно использовать в качестве инструментов как в мирное время, так и в конфликтных сценариях, для поддержки усилий в процессе достижения стабильности и безопасности. 


\section{Литература}

Cottey, Andrew, and Anthony Forster. "Introduction to Reshaping Defence Diplomacy: New Roles for Military Cooperation and Assistance." In Reshaping Defence Diplomacy: New Roles for Military Cooperation and Assistance. London: Routledge, Chapman \& Hall, 2004.

Defence, United Kingdom Mi. Defence Diplomacy, Policy Paper 1. MoD , 2000.

Harnisch, Sebastian, and Hanns W. Maull. "Conclusion: Learned its Lesson Well? Germany as a Civilian Power Ten Years after Unification." In Germany as a Civilian Power: The Foreign Policy of the Berlin Republic, 128-56. Manchester: Manchester University Press, 2001.

Roberts, Walter R.. "What is Public Diplomacy? Past Practices, Present Conduct, Possible Future." Mediterranean Quarterly 18, no. 4 (2007): 37.

Runge, Peter. "Helfer in Uniform? Militäreinsätze in der humanitären Hilfe." Wissenschaft \& Frieden, special issue on "Zivil-militärische Zusammenarbeit, no. 4 (2006).

Shea, Timothy C.. "Transforming Military Diplomacy." Joint Force Quarterly 38, no. 50 (2005).

Streichert, Christine. Deutschland als Zivilmacht In Trierer Arbeitspapiere zur Internationalen Politik . Vol. 11 . Trier: Universität Trier, 2005.

von Clausewitz, Carl. On War. Project Gutenberg E-Book No. 1946, 2006. 